\title{
Does Program Compliance with CDIO Warrant Automatic Compliance with CEAB Accreditation Criteria for 2014?
}

\author{
George Platanitis and Remon Pop-Iliev \\ University of Ontario Institute of Technology \\ george.platanitis@uoit.ca \\ remon.pop-iliev@uoit.ca
}

\begin{abstract}
An accreditation board takes the responsibility of evaluating an institute's engineering program, granting it accreditation upon the satisfaction that it meets a minimum standard in terms of academic and professional quality of the faculty, laboratories, equipment, computing facilities, and students' work within the engineering curriculum. In Canada, the Canadian Engineering Accreditation Board (CEAB) ensures that engineering programs meet the necessary educational standards as acceptable for licensure, and that engineering education delivered by the institute continues to improve. In recent years, accreditation boards have prescribed "outcome-based" assessments of engineering design curriculums. These criteria focus on the ability of students to apply knowledge of mathematics, science, and engineering science, extending to designing and conducting experiments, analyzing data, as well as developing a system, component, or process to meet certain needs. A recent approach that has been introduced to provide a better learning experience for engineering students and to educate them as well-rounded engineers to be able to develop complex, value-added engineering products and processes is the CDIO (Conceive-DesignImplement-Operate) approach. This approach has been adapted by several universities within their engineering departments. But should a program's compliance with the CDIO standards warrant automatic compliance with CEAB (Canadian Engineering Accreditation Board) accreditation standards? Following the CDIO approach and using the outcome-based standards of accreditation boards may suggest so. Herein, we will provide an assessment of the Mechanical Engineering program in terms of the CDIO approach and look at its relationship with the CEAB standards.
\end{abstract}

\section{Introduction}

In recent years, accreditation boards have been prescribing "outcome-based" assessments of the engineering curriculum, ensuring that students gain the ability to apply knowledge of mathematics, science, and engineering science as mandated by industry, such that students must be able to develop a system, component, or process to meet certain needs. With this increasing demand for knowledge application in the development of viable products, engineering design has thereby become an integral and important part of engineering curricula. These points are exemplified by Kumar et al [1], where the authors review ABET requirements to identify barriers in incorporating sustainability in the undergraduate engineering program at Michigan Tech. Barriers include "bean counting" as opposed to process improvement (prior to ABET 2000), conventional faculty thinking, company expectations, and recruiting trends.

A recently developed approach which has been quick to be adopted by several institutes is the CDIO approach [2-4]. This approach was developed by the collaborative efforts of the Royal Institute of Technology (Sweden), Linköping University (Sweden) and the Massachusetts Institute of Technology (USA) [2, 3], which have been running a joint four-year program to develop a model for engineering education, focusing on CDIO skills. The purpose of this program is to provide students with an education that stresses fundamental engineering systems and to sustain productivity, innovation and excellence. The CDIO approach defines the levels of creating a design as follows [2]:

- Conceive - defining the need and technology, considering the enterprise strategy and regulations, developing the concept, architecture, and business case.

- Design - creating the plans, drawings, and algorithms that describe what will be implemented.

- Implement - transforming the design into the product, including manufacturing, coding, test and validation. 
- Operate - using the implemented product to deliver the intended value, including maintaining, evolving and retiring the system.

Such an approach allows students, for example, to learn about conceiving a product as startup companies do, as well as exercise engineering reasoning to solve problems that are open-ended and ill-defined.

Since its inception, CDIO has been quickly adopted by institutes in Denmark (2002), Canada, South Africa, United Kingdom, and the USA (2003) in their engineering programs [5]. Three goals have been determined for the CDIO endeavour:

- Master a deep working knowledge of technical fundamentals

- Lead in the creation and operation of new products and systems

- Understand the importance and strategic value of their future research work

The initiative provides students with an education that stresses fundamentals in terms the four CDIO levels. Each of the four founding institutes adopted the CDIO Initiative in a variety of engineering programs: vehicle (KTH), aerospace (MIT), mechanical (Chalmers), and applied physics and electronics (LiU). For each of the four CDIO themes, program outcomes were identified for both programmatic and student experience levels Curriculum (engineering program outcomes and CDIO skills education), Teaching and Learning (active and hands-on learning, feedback and research into teaching and learning approaches), Laboratories and Workshops (building and best-use), and Assessment (identifying clear goals and outcomes, assessment of skills, and programmatic evaluation).

This paper will examine the Mechanical Engineering program at UOIT against the twelve CDIO standards. Further, the program's degree of compliance to the CDIO standards will be compared with current $\mathrm{CEAB}$ criteria for accreditation of engineering programs [6] and correlations between the CEAB criteria and CDIO standards will be determined.

\section{Background}

Industry demands, as well as rapid changes to encompassing technical and social drivers, constantly challenge engineering education. To meet these needs, accreditation boards have developed standards with which to evaluate post-secondary engineering programs to ensure that graduating students are able to apply technical and non-technical knowledge to the design and development of products and systems that fulfill various needs. But if an engineering program is compliant with the CDIO standards, is it automatically compliant with accreditation criteria? In one example, the Mechanical Engineering program at Chalmer's
University of Technology (Sweden) was evaluated using the quality assurance system prescribed by the CDIO model and compared to the accreditation requirements of EUR-ACE (European Standards for Accreditation of Engineering Programs) [7]. The conclusion drawn by the author was that the CDIO system provided a more comprehensive and encompassing view of engineering than that of EURACE, by considering the full product/system/process lifecycle.

In this paper, the authors evaluate the Mechanical Engineering program at UOIT against the CDIO Standards, as well as the most recent accreditation criteria prescribed by CEAB [6], with correlations determined between the two to determine whether CDIO compliance means an automatic compliance with accreditation criteria.

\section{The CDIO Standards}

The CDIO initiative was developed to reconcile the tension between two growing needs - demand of graduating students to embody an increasing amount of technical knowledge, and the recognition that young engineers must possess an array of personal, interpersonal, and system building knowledge and skills [8]. As a result, the CDIO Syllabus [8, 9] was created to provide a template and process which can be customized to any undergraduate engineering program.

The Syllabus summarizes formally the set of knowledge, skills, and attitudes desired of future young engineers desired by industry, alumni, and academia, setting clear, complete and consistent goals for undergraduate engineering education that are well understood and can be implemented by engineering faculty $[8,9]$. The four parts of the Syllabus each encompass the four expectations of engineering graduates [9] and are summarized at the first level of detail:

- Part 1 - Technical Knowledge and Reasoning

- Part 2 - Personal and Professional Skills and Attributes

- Part 3 - Interpersonal Skills

- Part 4 - Conceiving, Designing, Implementing, and Operating Systems in the Enterprise and Societal Context.

In January 2004, the CDIO Initiative adopted 12 standards to describe CDIO programs [10], all of which serve four purposes:

- Define distinguishing features of a CDIO program.

- Serve as guidelines for educational program reform and evaluation. 
Table 1. Summary of the twelve CDIO Standards.

\begin{tabular}{|c|c|c|c|}
\hline 1 & $\begin{array}{l}\text { CDIO as Context } \\
\text { Adoption of the principle that prodyct and system lifecycle } \\
\text { development and deployment - Conceiving, Designing, } \\
\text { Implementing and Operating - are the context for engineering } \\
\text { education. }\end{array}$ & 7 & $\begin{array}{l}\text { Integrated Learning Experiences } \\
\text { Integrated learning experiences that lead to the acquisition of } \\
\text { disciplinary knowledge, as well as personal, interpersonal, and } \\
\text { product and system building skills. }\end{array}$ \\
\hline 2 & $\begin{array}{l}\text { CDIO Syllabus Outcomes } \\
\text { Specific, detailed learning outcomes for personal, } \\
\text { interpersonal, and product and system building skills, } \\
\text { consistent with program goals and validated by program } \\
\text { stakeholders. }\end{array}$ & 8 & $\begin{array}{l}\text { Active Learning } \\
\text { Teaching and learning based on active experiential learning } \\
\text { methods. }\end{array}$ \\
\hline 3 & $\begin{array}{l}\text { Integrated Curriculum } \\
\text { A curriculum designed with mutually supporting disciplinary } \\
\text { subjects, with an explicit plan to integrate personal, } \\
\text { interpersonal, and product and system building skills. }\end{array}$ & 9 & $\begin{array}{l}\text { Enhancement of Faculty CDIO Skills } \\
\text { Actions that enhance faculty competence in personal, } \\
\text { interpersonal, and product and system building skills. }\end{array}$ \\
\hline 4 & $\begin{array}{l}\text { Introduction to Engineering } \\
\text { An introductory course that provides the framework for } \\
\text { engineering practice in product and system building, and } \\
\text { introduces essential personal and interpersonal skills. }\end{array}$ & 10 & $\begin{array}{l}\text { Enhancement of Faculty Teaching Skills } \\
\text { Actions that enhance faculty competence in providing integrated } \\
\text { learning experiences, in using active experiential learning } \\
\text { methods, and in assessing student learning. }\end{array}$ \\
\hline 5 & $\begin{array}{l}\text { Design-Build Experience } \\
\text { A curriculum that includes two or more design-build } \\
\text { experiences, including one at a basic level and one at an } \\
\text { advanced level. }\end{array}$ & 11 & $\begin{array}{l}\text { CDIO Skills Assessment } \\
\text { Assessment of student learning in personal, interpersonal, and } \\
\text { product and system building skills, as well as in disciplinary } \\
\text { knowledge. }\end{array}$ \\
\hline 6 & $\begin{array}{l}\text { CDIO Workspaces } \\
\text { Workspaces and laboratories that support and encourage } \\
\text { hands-on learning of product and system building, } \\
\text { disciplinary knowledge, and social learning. }\end{array}$ & 12 & $\begin{array}{l}\text { CDIO Program Evaluation } \\
\text { A system that evaluates programs against these twelve standards, } \\
\text { and provides feedback to students, faculty, and other } \\
\text { stakeholders for the purposes of continuous improvement. }\end{array}$ \\
\hline
\end{tabular}

- Create benchmarks and goals with worldwide application.

- Provide a framework for continuous improvement.

Table 1 summarizes these standards.

\section{Canadian Engineering Accreditation Board (CEAB) Criteria}

To ensure that engineering programs in Canada are delivering the necessary quality and content in engineering education so that graduating students gain the necessary technical, personal, and interpersonal skills needed in entering the workforce once they graduate, the CEAB established several criteria that engineering programs are evaluated against in order to grant those programs accreditation. Table 2 summarizes these criteria according to the 2010 requirements [6]. These requirements must be fully complied with by 2014 for the engineering program to maintain its accreditation status.

\section{UOIT's Mechanical Engineering Program}

At UOIT, students entering the engineering program have a choice of three mechanically-oriented engineering fields - Mechanical Engineering (with a choice of Comprehensive, Energy, or Mechatronics specialization), Manufacturing, and Automotive. All three fields contain common subject areas in mathematics, chemistry, physics, statics and dynamics, economics, thermodynamics, fluid mechanics, communications, environmental sciences, as well as humanities, law, ethics, and professionalism. Each field also contains common core design courses which include design-build components of various levels of difficulties, as well as program specific design courses (for example, Advanced Mechatronics in the Mechatronics option). In their third year, students begin taking more specific courses to their chosen specializations. By their fourth year, students' programs consist of courses almost entirely specific to their respective fields, including their programspecific capstone courses.

The Mechanical Engineering program at UOIT is continually evolving to better meet the industry needs of graduating students possessing the necessary technical, personal, interpersonal, and system building skills. To help accomplish this, the CDIO Standards can be used to guide the development of the program in meeting the learning outcomes. But does a CDIO compliant program mean that it should be automatically accredited? In the following, UOIT's Mechanical Engineering program is evaluated against the CDIO Standards, with correlations made between the Standards and the accreditation criteria. For each of the 12 CDIO Standards, a description is provided as to whether or not, as well as how, the Mechanical Engineering program meets the requirement and they are summarized below: 
Table 2. CEAB accreditation criteria.

\begin{tabular}{|l|}
\hline \multicolumn{1}{|c|}{ Accreditation Criteria } \\
\hline 3.0 Continual Improvement \\
\hline 3.1 Graduate Attributes \\
3.1.1 A knowledgebase for engineering \\
3.1.2 Problem analysis \\
3.1.3 Investigation \\
3.1.4 Design \\
3.1.5 Use of engineering tools \\
3.1.6 Individual and teamwork \\
3.1.7 Communication Skills \\
3.1.8 Professionalism \\
3.1.9 Impact of engineering on society and the \\
environment \\
3.1.10 Ethics and equity \\
3.1.11 Economics and project management \\
3.1.12 Life-long learning \\
\hline 3.2 Students \\
3.2.1 Admission \\
3.2.2 Promotion and graduation \\
3.2.3 Counselling and guidance \\
3.2.4 Degree auditing \\
\hline 3.3 Curriculum Content \\
3.3.1 Approach and methodologies for quantifying \\
curriculum content \\
\hline 3.4 Program Environment \\
3.4.1 Quality of the education experience \\
3.4.2 Faculty \\
3.4.3 Leadership \\
3.4.4 Expertise and competence of faculty \\
3.4.5 Professional status of faculty members \\
3.4.6 Financial resources \\
3.4.7 Authority and responsibility for the engineering \\
program \\
3.4.8 Curriculum committee \\
\hline
\end{tabular}

Standard 1 - At this point, a mission statement or approved documentation is needed to help officially recognize the Mechanical Engineering program as a CDIO program.

Standard 2 - Through core, complementary, and program specific courses, students learn various mathematics, science, engineering, interpersonal, teamwork, and communication skills, along with knowledge in engineering business, societal impact, and engineering law and ethics, which they ultimately apply to the design, development, implementation and operation of a product for its entire lifecycle.

Standard 3 - The Mechanical Engineering program is fully integrated with both technical and non-technical learning as applied to the engineering field, and includes design-build group projects shared across multiple courses. Examples include the integrated design project of third-year Computer-Aided Design with Kinematics and Dynamics of Machines, where students design a system by applying skills learned in both courses (including but not limited to CAD design and analysis, kinematics, dynamics, simulation, and detailed design and validation) as well as capstone design groups/projects spread across multiple disciplines.

Standard 4 - All Mechanical Engineering fields have a common first-year curriculum, in which students are introduced to applicable mathematics, science, humanities, and communication skills, and are introduced to the concept of engineering design and development.

Standard 5 - Students are afforded the opportunity to take core and complementary courses requiring them to engage in design-build projects (individually and in groups), which increase in level of difficulty each year, from a simple design-build and feasibility analysis in first-year to full product lifecycle considerations at the capstone level. Engineering programs at UOIT also offer an internship program (12-16 month placement) following third-year, as well as co-op program (3-4 month placement) to provide students with co-curricular experiences in engineering $[11,12]$.

Standard 6 - Several facilities equipped with the latest tools and technologies are readily available to support hands-on learning for engineering students. These include the Integrated Engineering Design Centre, a Component Design Laboratory, the Energy Centre, a Solid Mechanics and Materials Laboratory, a Dynamics, Kinematics and Vibrations Laboratory, a Manufacturing Laboratory, and the Borehole Thermal Energy Storage Laboratory. An Integrated Manufacturing Centre is also a key laboratory to facilitate advanced learning in manufacturing, mechatronics, and engineering. Finally, mechanical, automotive, and manufacturing students have access to an engineering design laboratory and a computeraided design laboratory, equipped with workstations containing various $\mathrm{CAD}$ and analysis tools to facilitate the engineering design process and enhance student learning.

Standard 7 - In addition to technical knowledge, students are required to take a course dealing with science and technological impacts on society (for example, environmental and economic impacts), challenging them to critically think of remediation measures for existing problems and for the prevention of future problems. This course is taken during firstyear. Also, students learn about technical communication early in their academic careers. In fourth-year, students learn about engineering law and ethics. It is expected that students will apply these skills and knowledge throughout their academic program and beyond. 
Table 3. CEAB accreditation criteria with CDIO Standards related to each.

\begin{tabular}{|l|c|}
\hline \multicolumn{1}{|c|}{ Accreditation Criteria } & CDIO Standards Related to CEAB Criteria \\
\hline 3.0 Continual Improvement & $9,10,12$ \\
\hline 3.1 Graduate Attributes & 2,4 \\
3.1.1 A knowledgebase for engineering & $2,3,4,7,8$ \\
3.1.2 Problem analysis & $3,7,8$ \\
3.1.3 Investigation & $3,5,7$ \\
3.1.4 Design & $5,6,7,8$ \\
3.1.5 Use of engineering tools & $3,5,8$ \\
3.1.6 Individual and teamwork & $2,4,7$ \\
3.1.7 Communication Skills & 2,7 \\
3.1.8 Professionalism & 7 \\
3.1.9 Impact of engineering on society and the & 2,7 \\
environment & 2,7 \\
3.1.10 Ethics and equity & $3,5,7,8$ \\
3.1.11 Economics and project management & \\
3.1.12 Life-long learning & 2,11 \\
\hline 3.2 Students & \\
3.2.1 Admission & \\
3.2.2 Promotion and graduation & \\
3.2.3 Counselling and guidance & \\
3.2.4 Degree auditing & \\
\hline 3.3 Curriculum Content & \\
3.3.1 Approach and methodologies for quantifying & \\
curriculum content & \\
\hline 3.4 Program Environment & \\
3.4.1 Quality of the education experience & \\
3.4.2 Faculty & \\
3.4.3 Leadership & \\
3.4.4 Expertise and competence of faculty & \\
3.4.5 Professional status of faculty members & \\
3.4.6 Financial resources & \\
3.4.7 Authority and responsibility for the engineering & \\
program & \\
3.4.8 Curriculum committee & \\
\hline
\end{tabular}

Standard 8 - UOIT faculty strive to include active learning methods to provide students with practical, hands-on learning of concepts. These include in-class exercises, tutorial exercises for further practice (such as skills in sketching and conceptualizing), laboratory sessions, and design-build projects in core and complementary engineering courses.

Standard 9 - UOIT's Faculty of Engineering and Applied Science has internationally renowned professors in their respective disciplines and is committed to hiring the best and most talented personnel. Faculty also have opportunities and resources to enhance their professional development, including through industrial partnerships that have been established through PACE (Partners for the Advancement of Collaborative Engineering Education).

Standard 10 - Faculty members in FEAS at UOIT have many opportunities to enhance their competency in teaching, including use of the Teaching and Learning Centre on campus, as well as participation in education symposiums through conferences and organizations such as Engineering and Product Design Education (EPDE) and ASME. FEAS strives to hire and maintain faculty that are also effective as instructors.

Standard 11 - FEAS faculty use a number of means to evaluate achieved learning outcomes, including written examinations, oral presentations, written assignments and reports, as well as peer and self assessment. A recently developed tool currently being used in the core engineering design courses (including capstone) and some complementary design courses specific to each field is the ICE rubric [13, 14], with application to evaluation of group term design projects to provide a fair and objective manner of assessing the level of learning and application of skills and knowledge pertaining to each respective project.

Standard 12 - Tools available to FEAS to evaluate their engineering programs include course evaluations, industry reviews, as well as accreditation evaluation and reporting. UOIT's engineering programs are continually assessed to ensure delivery of learning 
outcomes for students as required by major stakeholders.

Table 3 shows which of the twelve CDIO Standards are relevant to guide the engineering program development to comply with the CEAB standards. It should be noted that the CDIO standards do not explicitly provide for items such as student admission into engineering, quantification of curriculum content, nor financial resource use. However, where program content is concerned, the CDIO Standards can be used to guide compliance for Graduate Attributes (Sec. 3.1) and Program Environment (Sec. 3.4).

\section{Conclusions}

UOIT's Mechanical Engineering program continues to develop and improve each year to provide high quality engineering education while complying with accreditation requirements. The CDIO Standards were used to identify content and delivery of the program, with relationships made between accreditation requirements and $\mathrm{CDIO}$ compliance. Many of the accreditation criteria prescribed by the CEAB can be achieved through compliance with the CDIO Standards, such as Graduate Attributes and Program Environment. Several accreditation criteria cannot be achieved via CDIO compliance, but a CDIO engineering program does achieve many of the attributes required by accreditation boards, positioning the program well to be accredited.

\section{Acknowledgements}

The authors would like to thank the Natural Sciences and Engineering Research Council (NSERC) of Canada and UOIT for financially supporting UOIT's Design Chair budget, part of which supported this research work. The authors are also grateful for the hardware and software provided by PACE (Partners for the Advancement of Collaborative Engineering Education).

\section{References}

[1] Kumar, V., Haapala, K. R., Rivera, J. L., Hutchins, M. J., Endres, W. J., Gershenson, J. K., Michalek, D. J., and Sutherland, J. W., "Infusing Sustainability Principles into Manufacturing/Mechanical Engineering Curricula," Journal of Manufacturing Systems, Vol. 24, No. 3, 2006, pp. 215225 .

[2] Brodeur, D. R., Crawley, E. F., Ingemarsson, I., Malmqvist, J., Östlund, S., "International Collaboration in the Reform of Engineering Education," American Society of Engineering Education Conference, Montreal, Canada, June 16-19, 2002. Session 2260.

[3] Gustafsson, G., Newman, D. J., Stafström, S., Wallin, H. P., "First-year Introductory Courses as a Means to Develop
Conceive - Design - Implement - Operate Skills in Engineering Education Programmes," Société Européenne pour la Formation des Ingénieurs (SEFI) Conference, Florence, Italy, September 8-11, 2002.

[4] Armstrong, P. J., Kee, R. J., Kenny, R. G., and Cunningham, G., "A CDIO Approach to the Final Year Capstone Project," 1st Annual CDIO Conference, Kingston, Ontario, June 7-8, 2005.

[5] Berggren, K., Brodeur, D., Crawley, E. F., Ingemarsson, I., Litant, W. T. G., Malmqvist, J., and Östlund, S., "CDIO: An International Initiative for Reforming Engineering Education," World Transactions on Engineering and Technology Education, Vol. 2, No. 1, 2003, pp. 49-52.

[6] Canadian Engineering Accreditation Board, "Accreditation Criteria and Procedures," 2010. Available at: http://www.engineerscanada.ca/e/files/Accreditation_Criteri a_Procedures_2010.pdf.

[7] Malmqvist, J., "A Comparison of the CDIO and EURACE Quality Assurance Systems," $5^{\text {th }}$ Annual CDIO Conference, Singapore Polytechnic, Singapore, June 7-10, 2009.

[8] Crawley, E. F., "The CDIO Syllabus: A Statement of Goals for Undergraduate Engineering Education," Department of Aeronautics and Astronautics, Massachusetts Institute of Technology, January 2001.

[9] Crawley, E. F., "Creating the CDIO Syllabus, A Universal Template for Engineering Education," $32^{\text {nd }}$ ASEE/IEEE Frontiers in Education Conference, Boston, MA, November 6-9, 2002.

[10] "World Wide CDIO Initiative Standards," January 2004. HTTP:

http://www.cdio.org/implementing-cdio-yourinstitution/standards.

[11] "Engineering Internship Program," HTTP: http://www.engineering.uoit.ca/undergraduate/internship/int ernship.

[12] "Engineering Coop Program," HTTP: http://www.engineering.uoit.ca/undergraduate/internship/coo p.

[13] Platanitis, G. and Pop-Iliev, R., "Establishing Fair Objectives and Grading Criteria for Undergraduate Design Engineering Project Work: An Ongoing Experiment," International Journal of Research and Reviews in Applied Sciences, Vol. 3, No. 5, December 2010, pp. 271-288.

[14] Platanitis, G., Pop-Iliev, R., and Nokleby, S., "Implementation and Effect of Rubrics in Capstone Design Courses," Proceedings of the ASME 2009 International Design Engineering Technical Conferences \& Computers and Information in Engineering Conference (IDETC/CIE), San Diego, CA, August 30-September 2, 2009. Paper No.: DETC2009-86996. 